\title{
Finding support for disruption: developing a digital humanities project in Mexico
}

\author{
Ernesto Priani Saisó \\ Facultad de Filosofía y Letras, \\ Universidad Nacional Autónoma de México (UNAM), Mexico City, Mexico
}

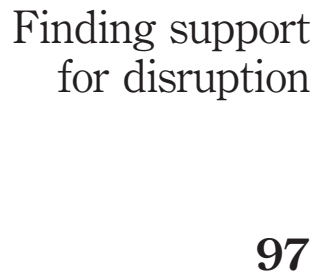

\begin{abstract}
Purpose - This paper seeks to provide a description and reflection on some of the structural problems and challenges faced when developing a digital humanities (DH) project in a Mexican public university.

Design/methodology/approach - As DH is a relatively new field and practice in Mexican academia, this article is based on a case study of developing the Biblioteca Digital de Pensamiento Novohispano (Digital Library of New Hispanic Thought). This is one of the few DH at the Universidad Nacional Autónoma de México (UNAM), the largest public university in the country.

Findings - It was found that there were three central problems for developing a DH project in a Mexican public university: existing technical knowledge and abilities at the UNAM will be challenged by $\mathrm{DH}$ projects; projects are the place to train human resources in DH methodology; and researchers need to consider different long-term infrastructure and hosting solutions, with or without using institutional infrastructure, at the same time researches need to work within the institution to establish a specific policy for research projects.

Practical implications - The paper concludes that the structure, goals and products of $\mathrm{DH}$ projects need to be modified and expanded in order to also consider alternative goals and products such as: proposals of institutional policy, creation of infrastructure and academic and student training. DH projects must be regarded as disruptive, that is that the project needs to assume rupture as a part of the project itself.

Originality/value - The experience of innovation and disruption is not necessarily the same in all fields and all institutions. This article documents for the first time the particular experiences of a public university in a developing country with $\mathrm{DH}$ projects. It has been found that the delay in using computers in the humanities in Mexico has led to the development of a specific paradox: a gap between institutional interest and disposition in the use of computers in humanities, and the lack of DH culture in those who have to develop the project.
\end{abstract}

Keywords Digital humanities, Public university, Mexico, Scholarly editing, Institutional support, Library projects, Digital libraries

Paper type Research paper

\section{Digital humanities overview}

The first use of computing for humanities research is usually attributed to Roberto Busa when in 1949 he began the task of creating and indexing Verborum of St Thomas Aquinas using computers (Hockey, 2004). From that moment, computers have been used increasingly in the humanities. After decades of work, the intersection of computing and humanities emerged as a new field known as Digital humanities (DH) or Humanities Computing (previously known as Literary and Linguistic Computing) (Hockey, 2004). Research in this area is not only theoretical it also has specific practical applications in diverse humanities disciplines such as history, literature and philosophy. Some of those

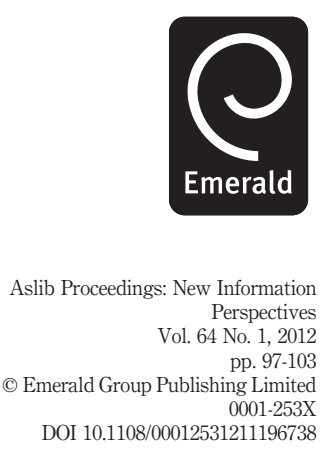


AP

64,1

98

practical applications are digital archives, texts collections, digital scholarly editions, and tools to search data in digitalized text. Over the past two decades numerous digital humanities projects of this kind have been developed in universities, mainly in Europe, the USA, and Canada. For example the Perseus project, Bivio On line, Codex Sinaiticus, Rossetti Archive, TaPor to mention only a few. In parallel several academic groups and organizations have been created, such as the Association for Literary and Linguistic Computing and the Society for Digital Humanities, as well as initiatives to produce standards for textual markup and information distribution, such as TEI (Text Encoding Initiative) and the OAI (Open Archives Initiative).

In Mexico and in Latin America in general, $\mathrm{DH}$ and scholarly editing are still fairly unknown. Relatively few projects have been developed and most of them do not adhere to international standards. We found that international standards and experience are a reference for some groups within the institutional structure of the university that provide the financial support, but not necessarily for the academic and technical staff involved in the development of the project. This point took on particular relevance when we attempted to develop a scholarly digital library within a public university in Mexico. As we shall see, this asymmetry is a central issue and helps to explain why digital humanities projects are welcome for their innovation but complicated because of their disruption.

\section{Mexican institutional context}

The Universidad Nacional Autónoma de Mexico (UNAM) has played a major role in the introduction of Internet and digital technologies in Mexico. The UNAM was one of the first two academic institutions to connect to the Internet in Mexico and, from there, has been at the forefront of digital culture dissemination. It was one of the original Internet service providers and is still an important developer, content, and security provider (Gayosso, 2003). Nevertheless, the use of information technologies within the UNAM's academic community has had a different history.

Similarly, to other universities around the world, computers and technology have been common tools for sciences and engineering and digital literacy is widespread in these fields within the Mexican academy. This is not the same case for the humanities. A few facts can illustrate this, for example, the UNAM has an Institute for Applied Mathematics and Systems that focuses on computer applications for the sciences and engineering, but there is no similar institution for Humanities Computing. The most important investment in recent years in computing infrastructure is the Laboratory for Super Computing and this is completely science oriented. There is no comparable investment in computing infrastructure for humanities.

In fact, computer culture within the humanities in the UNAM has been mainly associated with teaching rather than research. There is a strong institutional interest in developing new teaching models, that make use of computer technologies, and humanities disciplines have been benefited with funding and infrastructure for this purpose. Within the UNAM, there are a significant number of digital projects on virtual education and a great deal of work and discussion on the incorporation of digital tools in the classrooms.

The most important institutional digital projects involving the humanities are therefore related to teaching. This is also true for other higher education institutions in Mexico, both public and private. A special number on Internet and Teaching of the Revista Digital Universitaria, in November 2004 (RDU, 2004b) describes different practical 
applications of e-learning programs and strategies in the higher education environment. Of the projects that could be described as Digital Humanities, it is clear that they are linked to the development of institutional teaching programs and they tend to be viewed as computing applied to education rather than as DH projects in themselves. In July 2004 the Revista Digital Universitaria, published an issue on digital libraries (RDU, 2004a). In a similar way to e-learning applications, the articles on digital libraries demonstrate a particular institutional desire for developments and practical software applications and digital tools for information distribution focused on learning and teaching.

The use of digital tools has also focused on the dissemination of culture. The project Caza de letras a "poetry reality show", uses the public training/competition schema of the TV shows, with a web based tool, as a way to generate interest in creative writing. This project is a clear example of using digital projects for promoting and disseminating culture.

The development of strictly digital projects in humanities has been, in this institutional context, significantly sporadic. Early examples of digital humanities projects in the UNAM are: a CD digital edition of José Juan Tablada's poetry by Roberto Mata and a digital web edition of women's nineteenth century literary magazines. Recently the Revista Digital Universitaria published an issue on digital humanities (RDU, 2011).

Research is an institutional goal that needs to be accomplished by researchers that act with some independence from the institution itself. Education and dissemination are goals that the university pursues through institutional structures. Currently developing digital humanities projects depends, mainly on individual researchers or groups taking the initiative and developing and using new tools for the traditional objectives of their fields.

This individual nature of these initiatives explains why DH projects have been infrequent in Mexico. When projects rest on the interest, and formation of a single researcher or group, there are a number of inhibitory factors, which prevent the development of a major number of projects. In Mexico, those factors are, for example, the traditional book-centered-culture of the humanities, the exclusion of digital publication and digital humanities projects from the science incentive policy or the advanced average age of researchers, to name a few.

In the few cases where researchers have embarked on what is often an isolated DH project, as the case of the Biblioteca Digital del Pensamiento Novohispano (BDPH), the relationship between the institution and the development of the project becomes paradoxical. As Jordy Micheli has pointed out, after his experience developing a virtual education project at another Mexican public university, the Universidad Autónoma Metropolitana, the introduction of technology in the university environment has two aspects: one is innovation; the other is disruption (Micheli, 2009).

Innovation is a positive value for institutions like universities and is one of the factors that promotes new approaches to using technology to achieve traditional goals of research. However, disruption, the emergence of a completely new way of doing something, tends to challenge the traditional workings of an institution. Many of the problems that we encountered during the development of the BDPH, was the result of these two opposing elements, innovation and disruption. We found, during our experience of developing the BDPN, institutional disposition to stimulate innovation in humanities through financial and technical resources despite a lack of knowledge, experience, comprehension or institutional interest in the day-to-day process of the project.

\section{Finding support for disruption}

99 
AP

64,1

100

\section{The project}

The BDPN (www.bdpn.unam.mx) is a DH project on two levels. The first one is a collection of digital editions of TEI/XML marked up diplomatic transcriptions of XVII century books and documents published in Mexico related to a discussion on the nature of comets; a significant controversy that initiated scientific discussion in Mexico, and is now testimony of the transit from astrological discourse to an astronomical one.

On a second level, BDPN is a set of digital tools for research offering:

- an automatic indexation of terms, references, names, and dates marked up in the texts;

- a collaborative tool to make philological and interpretative annotations; and

- a group of resources that uses the complete index to provide information about persons, works quoted, meaning of old Spanish words and of technical astronomical and astrological concepts.

So far, is difficult to define the kind of digital editions provided by BDPN. Our initial goal was to create a collection of scholarly editions of these texts. An electronic scholarly edition has been defined as "the establishment of a text on explicitly stated principles and by someone with specialized knowledge about textual scholarship and the writer or writers involved. An edition is scholarly both because of the rigor with which the text is reproduced or altered and because of the expertise brought to bear on the task and in the offering of suitable introductions, notes, and textual apparatus" (Price, 2008). We assume that the establishment of the text (our transcription) has all the elements required in a scholarly edition. The study and interpretation of it, that is the basis of any scholarly edition, is present on two levels of annotation: the use of TEI markup, and the philological, and interpretative through the use of the annotation tool. In this sense, the BDPN is similar to other electronic scholarly editions, such as the Walt Whitman Archive, the Rossetti archives, or a project like NINES, a library and infrastructure project of peer review digital scholarly editions.

The central distinction between these projects and the BDPN is that the BDPN is an open work, in which the collection of documents, and the critical apparatus is something permanently under construction by collaboration; while the others projects are finished works that show the conclusions of a research group as they are not planning to add new material or to modify the critical apparatus. There are other differences. BDPN is a collection of markup transcriptions like Bivio on line or the Perseus project, but in contrast to these projects, our electronic library generates automatic indexes of certain terms, concepts, names, and data, defined by specific academic intentions. It has in common with Pico's Project and Boccaccio's project, both part of the Virtual Humanities Lab, the two levels of annotation, but they work on a single text in contrast to BDPBN's corpus of texts.

In synthesis, the BDPN is an open collaborative electronic edition of a corpus that is marked up for research on certain topics, with tools to analyze and study the works as a single work or as a part of a corpus. This digital edition allows us to do things that we cannot do on paper. For example, we can work with a larger group of documents than on paper, in order to retrieve an important amount of data to work with. With this data, we can automatically have cross-references between documents, and we can create relations between information about works quoted (for example) and the number of 
times that work is quoted in the corpus. Finally as an open and dynamic work, we can add new contributions over time, from anyone that works on the subject.

The project was developed with the collaboration of undergraduate and graduate students that helped with the transcription and mark up of the texts. The project received financial support from the UNAM itself through a program for innovation in education (PAPIME) and from CONACYT, a Mexican government institution that promotes research. For the technical development of the project, I chose the Digital Publishing department from the Academic Computing Services (Dirección General de Cómputo Académico) of the UNAM, a department that had participated in previous digital humanities projects. For hosting and other maintenance issues, the project has the support of the University Library Services (Dirección General de Bibliotecas). In short, the project received major institutional support.

\section{Learning}

The actual development of the project was a very different picture. All this institutional support was not really prepared for a DH project. Both the academic and the technical groups involved in the project had little or no experience creating DTD categories or using an international standard as TEI for XML markup. In fact, for an important segment of the participating group this was the first time they had explored the use of XML markup language as a part of a humanities project. The problem was not the technology itself but the specific application of it to the literary study of texts.

The major evidence of this was the technical decision to feed the database independently of the DTD markup. In fact, XML was never understood as the primary source of the content of the database. Reviewing the initial technical proposal, the focus was on the database architecture, and not on the process to read the XML with a parser in order to translate the syntactic analysis into a language that can be interpreted by the computer and kept in a database. This is the reason why the indexes in the first version of the project were created without using the XML markup and the web interface used a HTML file marked up beside the XML document. The XML file was in the end, only an abstract reference for the entire project instead of the base to retrieve the information, and the key to study the texts. This solution, it seems to me, was the result not only of the lack of knowledge or experience working with XML projects, but because the $\mathrm{DH}$ project was disruptive and challenged the institutional organization that responded constructing a database directly and not using XML as a source. This was more than a just a technological problem, it was in fact a question of using existing technical knowledge but in a different way as well as innovating methodologies and processes within the institution.

One of the consequences of this disruption was that the project in itself became a learning process. In order to clarify the procedures, the tools and methodology to use, and to evolve the initial DTD to a TEI schema, all the group involved needed to learn and practice new ways of working. This transformed the project into a workshop.

Warwick et al. (2007) noticed in their study about successful projects and good practices in DH that (projects interviewed) "also stressed how vital it had been to recruit the ideal RAs. These were, however, relatively difficult to find, as they had to have both disciplinary research expertise and good knowledge of digital techniques therefore, most RAs required training". One could assume however, that they could find people with good knowledge of digital techniques and the difficulty was in the

\section{Finding support for disruption}

101 
AP

64,1

102

combination of expertise. In our case, we found great difficulties in finding anyone with good knowledge of digital techniques. It was necessary to initiate all our RAs in that knowledge while working on the project.

The preexisting knowledge about digital humanities in researchers and undergraduate and graduate students in humanities in the UNAM was, and still is, limited. However, the major problem with working on the BDPN digital library project was that although they had some theoretical knowledge, there was little actual working experience on a $\mathrm{DH}$ project. In other words, all information and notion about digital humanities had been transmitted fragmented and without correlation to a practice. For all the participants in the project, it became the place to transform theory into experience and training. Until we have a critical mass of $\mathrm{DH}$ projects that can generate training programs in Mexico, we must consider the projects as autodidactic training programs.

The last problem we found developing the BDPN was the lack of institutional policies and infrastructure for DH research projects. The UNAM does not have a standard policy for digital projects. Different areas within the university have different policies and infrastructure. For instance, my faculty (Facultad de Filosofía y Letras) does not have policies or infrastructure to host digital projects even though it has infrastructure to run applications for scholar administration. The UNAM's Academic Computing Services does not have the policy of hosting faculty projects even though they develop the applications for those projects. As a solution, I asked the UNAM Library Services for help. Today the project is hosted there. However, there is no assurance that other DH projects may reach the same agreement with Library Services. Our agreement is an exception and there are no existing guidelines about hosting faculty projects within the library infrastructure.

Of course, it is the responsibility of the administration of the Faculty and the UNAM to create policies to support research digital projects; even so, this could happen only when $\mathrm{DH}$ projects reach the critical mass. Meanwhile DH projects will be disruptive to the primary goals of the administration, and we need to look for solutions beyond the traditional organization.

\section{Final thoughts}

Based on our experience we can summarize that DH projects in Mexican public universities will need to anticipate and overcome the following challenges in order to be successful:

(1) Existing technical knowledge and abilities will be challenged by DH projects.

(2) Projects will be the place to train human resources in $\mathrm{DH}$ methodology.

(3) Researchers need to consider different long-term infrastructure and hosting solutions, with or without using institutional infrastructure, at the same time researches need to work within the institution to establish a specific policy for research projects.

DH projects in public universities in Mexico are certainly welcome due to their innovative aspects. The disruptive aspects of $\mathrm{DH}$ projects, on the other hand, create difficulties and obstacles towards achieving stated research goals. Researchers need to consider that developing a $\mathrm{DH}$ project involves not only research work, but also, solving institutional organization difficulties to be successful. This is central: $\mathrm{DH}$ 
projects cannot be conceived solely as research products that result in for example, a Digital Library. Other results will be related to how to transform disruption into an opportunity: introduction of new procedures and technology, training and production of policies or institutional solutions to a problem. It will be useful that DH projects include these other goals from the beginning. New approaches in technology can also lead to new approaches in the organization of an institution.

\section{References}

Gayosso, B. (2003), “Cómo se conectó México a Internet", Revista Digital Universitaria, Vol. 5 No. 5, 1 October, available at: www.revista.unam.mx/vol.4/num5/art10/art10.html (accessed 2 April 2010).

Hockey, S. (2004), "The history of humanities computing", in Schreibman, S., Siemens, R. and Unsworth, J. (Eds), A Companion to Digital Humanities, Blackwell, Oxford, available at: www.digitalhumanities.org/companion/ (accessed 2 April 2010).

Micheli, J. (2009), Educación virtual y aprendizaje instititucional, Universidad Autónoma Metropolitana, Mexico City.

Price, K.M. (2008), "Electronic Scholarly Editions", in Schreibman, S., Siemens, R. and Unsworth, J. (Eds), A Companion to Digital Literary Studies, Blackwell, Oxford, available at: www. digitalhumanities.org/companionDLS/ (accessed 10 January 2011).

RDU (2004a), "Revista Digital Universitaria”, RDU, Vol. 5 No. 6, July 10, available at: www. revista.unam.mx/indexjul04.html (accessed 2 April 2010).

RDU (2004b), "Revista Digital Universitaria", RDU, Vol. 5 No. 10, November 10, available at: www.revista.unam.mx/indexnov04.html (accessed 2 April 2010).

RDU (2011), "Revista Digital Universitaria”, RDU, Vol. 12 No. 7, November 10, available at: www.revista.unam.mx/index_jul11.htm (accessed 27 July 2011).

Warwick, C., Terraas, M., Hintington, P. and Pappa, N. (2007), "The master builders: LAIRAH research on good practice in the construction of digital humanities projects", Literary and Linguistic Computing, Vol. 23 No. 3, pp. 383-96.

\begin{abstract}
About the author
Ernesto Priani Saisó has tenure in philosophy at the Philosophy Faculty at the Universidad Nacional Autónoma de México. He teaches Medieval and Renaissance Philosophy. These days he is researching on early modern Mexican thinkers and the survival of renaissance thought in them. The Biblioteca Digital del Pensamiento Novohispano (Digital Library of Neohispanic Thought) is part of his research. He worked as a digital editor working in 1998 for one of the first web designing companies in Mexico and was the chief editor of sites such as Microsoft's official site for Latin America, the internet service provider, Universo Estudiantil, and many others. From 2003 until 2008 he was the editor of the Revista Digital Universitaria, an online magazine designed to improve online creativity. At the present time, and besides teaching at the UNAM, he hosts the radio broadcast Ráfagas de pensamiento, for the University Radio Channel, Radio UNAM. He is a member of the Worldwide Advisory Board of the Virtual Humanities Lab at Brown University. Ernesto Priani Saisó can be contacted at: epriani@gmail.com
\end{abstract}

\footnotetext{
To purchase reprints of this article please e-mail: reprints@emeraldinsight.com
} Or visit our web site for further details: www.emeraldinsight.com/reprints

\section{Finding support for disruption}

103 